\title{
M. Benoît, J.-P. Deffontaines, S.Lardon, Acteurs et territoires locaux: vers une géoagronomie de l'aménagement
}

Paris, Inra-QUAE, 2006

Jean-Pierre Husson

\section{OpenEdition \\ Journals}

Édition électronique

URL : http://journals.openedition.org/rge/226

DOI : $10.4000 /$ rge.226

ISSN : $2108-6478$

Éditeur

Association des géographes de l'Est

Édition imprimée

Date de publication : 1 avril 2007

ISSN : 0035-3213

\section{Référence électronique}

Jean-Pierre Husson, « M. Benoît, J.-P. Deffontaines, S.Lardon, Acteurs et territoires locaux : vers une géoagronomie de l'aménagement », Revue Géographique de l'Est [En ligne], vol. 47 / 2 | 2007, mis en ligne le 21 décembre 2009, consulté le 22 septembre 2020. URL : http://journals.openedition.org/rge/ 226 ; DOI : https://doi.org/10.4000/rge.226

Ce document a été généré automatiquement le 22 septembre 2020.

Tous droits réservés 
M. Benoit, J.-P. Deffontaines, S.Lardon, Acteurs et territoires locaux : vers une géoagronomie de l'aménagement

Paris, Inra-QUAE, 2006

Jean-Pierre Husson

\section{RÉFÉRENCE}

M. BENOÎT, J.-P. DEFFONTAINES, S. LARDON, Acteurs et territoires locaux : vers une géoagronomie de l'aménagement, Collection Savoir-faire, Paris : Inra-QUAE, 2006, 174 p. ISBN 2-7380-1225-6, $35 €$. 
1 Ce livre court, dense, bien illustré permet de passer des frontières, de relier les géosystèmes aux agrosystèmes, bref de comprendre, en prenant en compte la confrontation des échelles, les stratégies des exploitations. La géoagronomie systémique, souvent investigatrice par la pluralité des scénarii qu'elle autorise, est une discipline d'aménagement et d'ingénierie territoriale. Elle est au service de la régulation des territoires ruraux et de la transmission des fermes.

Dès la préface, Edgard Pisani souligne que les zones non urbaines ne sont pas à percevoir en négatif, en reste mais qu'il s'agit d'espaces de vie dont le sens est réapproprié avec l'affirmation des formes de métropolisation.

Conçu comme un guide pratique, ce livre

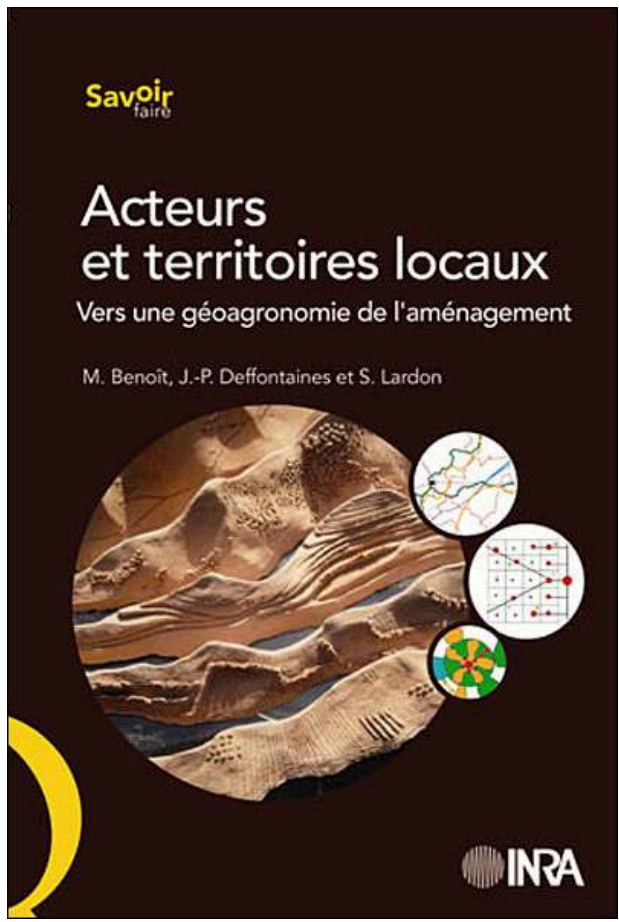
est le fruit d'une longue expérience et de connivences étroites entretenues entre les auteurs. Il se découpe en trois parties et se termine par un itinéraire méthodologique bâti sur des études d'aménagement intégrées : la communauté de communes du Valdonnez en Lozère et le pays de BasséeMontois localisé entre Provins et Sens. Le livre débute par l'énoncé des caractéristiques d'un territoire de projet, approprié, socialisé, porteur d'enjeux (qualité des eaux, biodiversité, risques). Le territoire du géoagronome est destiné à produire, protéger, accueillir. Organisé en mosaïques, il est diagnostiqué, approché de façon multiscalaire. Pour être compréhensible, il est traduit en modélisations graphiques placées entre chorèmes et SIG qui sont des outils, des aides à la décision. Cela offre l'avantage de fournir un langage partagé à propos d'un objet géographique transdisciplinaire, perçu à plusieurs échelles (parcelles, exploitations, bassins) qui interagissent entre elles. Cela sert encore à raisonner sur les territoires, à interpréter les stratégies d'acteurs et à les traduire dans l'espace et dans le temps. L'analyse des paysages est au cœur de cette démarche. Objet de connaissances, de représentation et de communication (p. 69), le paysage s'énonce avec le diagnostic géoagronomique, les UAP (unités agrophysionomiques), enfin l'analyse des marges et des bordures.

4 La compréhension des territoires, si possible portés par l'ambition de durabilité, s'observe au mieux à l'échelle de l'exploitation définie par ses pratiques, ses combinaisons d'assolement et de cultures, ses clôtures, points d'eau, fossés, drains. L'organisation de l'exploitation évolue au gré des itinéraires techniques retenus. Outre la SAU, elle abrite aussi des linéaires et des espaces intersticiels flous. Tout cela est pensé en fonction du calendrier de travail (productivité) et de l'étalement des risques. Cette démonstration est étayée par des études de cas modélisées (formes radiales, auréolaires, en enfilade, en mosaïque) (p. 107). L'organisation spatiale énoncée permet d'approcher la fonctionnalité des exploitations par une entrée porteuse ; ici, la qualité de l'eau ; là, le risque d'embroussaillement, etc. Résolument placé entre aménagement et réflexion sur le "ménagement» des territoires ruraux, ce livre d'ingéniérie 
territoriale relie acteurs, formes de mise en valeur et SAU. Il offre des clés aux décideurs pour mettre en œuvre des démarches intégrées, respectueuses de la prise en compte des externalités positives qui accompagnent toute démarche d'aménagement par définition prudente. 